\title{
PROTEINORRAQUIA TOTAL. VARIAÇÕES RELACIONADAS AO SEXO E À IDADE
}

\author{
A. SPINA-França * \\ ISAAC AMAR **
}

Em comparação a outros métodos de determinação da taxa de proteínas totais do líquido cefalorraqueano (LCR), o método turbidimétrico do ácido tricloracético ${ }^{1}$ adaptado para leitura espectrofotométrica apresenta grande viabilidade prática ${ }^{7}$.

A diversidade de valôres referidos como normais para a proteinorraquia total é em grande parte devida ao emprêgo de métodos de dosagem diferentes. Em vista disso foi feita a exploração da normalidade em relação ao método referido, estabelecendo-se os limites das variações fisiológicas ${ }^{5}$. Ulteriormente foram estudadas para o mesmo método as variações da proteinorraquia total na dependência do local de colheita da amostra ${ }^{6}$.

Na publicação presente, nova série de casos é analisada no sentido de estudar como se caracterizam em relação a êsse método as variações da proteinorraquia devidas à idade e ao sexo dos pacientes.

\section{MATERIAL E MÉTODO}

Os valôres da concentração protēica total do LCR de 1.011 pacientes foram utilizados para o presente estudo. A influência do fator etário foi investigada pela distribuição dos dados segundo grupos etários. Os grupos reuniam pacientes entre 3 meses e 70 anos de idade. A influência do sexo foi estudada por meio da análise dos dados referentes aos 596 dêsses pacientes que apresentavam idade entre 16 e 50 anos.

As amostras de LCR foram colhidas da cisterna magna (punção suboccipital) e eram normais quanto à pressão, aspecto, côr, citologia e proteinorraquia total. Em tôdas eram negativas as reações de Pandy, coloidal de Takata-Ara e de fixaçāo do complemento para sifilis e para cisticercose.

A proteinorraquia total foi determinada pelo método turbidimétrico do ácido tricloracético adaptado para leitura espectrofotométrica, segundo a técnica descrita em publicação anterior ${ }^{6}$.

Trabalho da Clínica Neurológica da Fac. Med. da Univ. de São Paulo (Prof. Adherbal Tolosa): *Assistente-doutor; ** Médico estagiário.

Nota dos autores - Agradecemos à técnica Sra. Izette C. Cunha a cooperação prestada na elaboração dêste trabalho. 


\section{RESULTADOS}

No quadro 1 são apresentados os resultados obtidos para a concentração do LCR distribuída segundo a idade dos pacientes. Os grupos etários compreendem períodos de 5 anos, entre 5 e 70 anos de idade. Os pacientes mais jovens foram grupados segundo a idade entre 3 e 6 meses, 6 e 12 meses, entre 1 e 2 anos e entre 2 e 5 anos.

Os dados que permitiram o estudo da influência do sexo e as estimativas correspondentes são apresentados no quadro 2.

\begin{tabular}{|c|c|c|c|c|c|c|c|c|c|c|c|}
\hline \multirow{2}{*}{ Idade } & \multirow{2}{*}{$\begin{array}{c}N^{\circ} \text { de } \\
\text { casos }\end{array}$} & \multicolumn{10}{|c|}{ Proteinas totais $(\mathrm{mg} / 100 \mathrm{ml})$} \\
\hline & & $4-6$ & $7-9$ & $10-12$ & $13-15$ & $16-18$ & $19-21$ & $22-24$ & $25-27$ & $28-30$ & Média \\
\hline 3- 6 meses & 21 & 0 & 0 & 0 & 2 & 3 & 2 & 2 & 5 & 7 & 23,9 \\
\hline 6-12 meses & 23 & 1 & 1 & 3 & 0 & 6 & 5 & 5 & 2 & 0 & 18,1 \\
\hline 1- 2 anos & 34 & 0 & 2 & 4 & 9 & 7 & 2 & 5 & 3 & 2 & 17,6 \\
\hline 2- 5 anos & 66 & 0 & 2 & 11 & 20 & 12 & 7 & 7 & 3 & 4 & 16,8 \\
\hline $6-10$ anos & 73 & 1 & 2 & 10 & 21 & 19 & 11 & 5 & 3 & 1 & 16,4 \\
\hline 11-15 anos & 92 & 0 & 3 & 9 & 22 & 23 & 13 & 14 & 6 & 2 & 17,5 \\
\hline $16-20$ anos & 126 & 0 & 3 & 3 & 26 & 43 & 23 & 15 & 12 & 1 & 18,2 \\
\hline $21-25$ anos & 116 & 0 & 3 & 12 & 30 & 30 & 20 & 12 & 4 & 5 & 17,3 \\
\hline $26-30$ anos & 98 & 0 & 1 & 14 & 19 & 27 & 20 & 6 & 6 & 5 & 17,6 \\
\hline 31-35 anos & 85 & 0 & 1 & 6 & 17 & 25 & 15 & 6 & 8 & 7 & 18,7 \\
\hline $36-40$ anos & 75 & 0 & 1 & 8 & 12 & 20 & 15 & 8 & 8 & 3 & 18,5 \\
\hline $41-45$ anos & 48 & 0 & 0 & 2 & 9 & 13 & 9 & 9 & 5 & 1 & 19,1 \\
\hline $46-50$ anos & 48 & 0 & 0 & 0 & 11 & 10 & 5 & 12 & 6 & 4 & 20,2 \\
\hline 51-55 anos & 37 & 0 & 0 & 0 & 5 & 12 & 9 & 4 & 2 & 5 & 20,1 \\
\hline $56-60$ anos & 33 & 0 & 1 & 0 & 2 & 7 & 7 & 5 & 6 & 5 & 21,6 \\
\hline $61-65$ anos & 24 & 0 & 0 & 0 & 1 & 2 & 7 & 5 & 7 & 2 & 22,5 \\
\hline $66-70$ anos & 12 & 0 & 0 & 0 & 0 & 0 & 4 & 2 & 4 & 2 & 24,0 \\
\hline
\end{tabular}

Quadro 1 - Distribuição da taxa de proteinas totais do LCR da cisterna magna segundo a idade (1.011 casos) e as médias respectivas. 


\begin{tabular}{ccc}
\hline $\begin{array}{c}\text { Proteinas totais } \\
(\mathrm{mg} / 100 \mathrm{ml})\end{array}$ & \multicolumn{2}{c}{ Sexo } \\
\cline { 2 - 3 } & Masculino & Feminino \\
\hline $7-9$ & 1 & 8 \\
$10-12$ & 45 & 31 \\
$13-15$ & 79 & 79 \\
$16-18$ & 62 & 89 \\
$19-21$ & 36 & 45 \\
$22-24$ & 33 & 32 \\
$25-27$ & 15 & 16 \\
$28-30$ & 285 & 11 \\
\hline Número de casos & 19,3 & 311 \\
Média (mg/100 ml) & 4,7 & 17,3 \\
Desvio padrão & & 4,8 \\
\hline
\end{tabular}

Quadro 2 - Distribuição, segundo o sexo, da taxa de proteinas totais do LCR de 596 casos; valor médio da proteinorraquia total e desvio padräo correspondente.

\section{COMENTARIOS}

Em relação ao mesmo método empregado neste estudo, a concentração protêica do LCR ao nível da cisterna magna varia entre 5 e $30 \mathrm{mg}$ por $100 \mathrm{ml}$. Esses limites foram estabelecidos pela análise dos dados referentes a 676 casos. O valor médio registrado para êsses casos foi de 17,0 $\mathrm{mg}$ por $100 \mathrm{ml}^{6}$. Em relação aos limites máximo e mínimo citados foram selecionados os casos utilizados no presente estudo para verificar a influência da idade e do sexo dos pacientes sôbre a proteinorraquia total.

Influência da idade - Diniz ${ }^{3}$ demonstrou que é aos três meses de idade que o LCR assume os caracteres encontrados para o adulto em condições normais. Abaixo dessa idade, a interrelação de diversos fatôres leva a crer que o LCR seja diferente daquele do adulto. Entre as diferenças, salienta-se a hiperproteinorraquia. Esta tende a desaparecer com a idade. Diniz verificou que já aos dois meses de idade a concentração protêica do LCR não difere de modo significativo daquela encontrada para o adulto.

Por outro lado, a proteinorraquia total tende a aumentar na senescência. Madonick ${ }^{4}$ verificou que para 98 pacientes cuja idade se distribuia 
entre 65 e 94 anos a concentração protêica do LCR era representada pela média de $33,8 \mathrm{mg}$ por $100 \mathrm{ml}$.

Tendo em vista a hiperproteinorraquia própria ao período neonatal e da senescência que podem ser representadas por concentrações que escapam aos limites admitidos como normais, a exploração feita neste estudo teve como limites os valôres extremos de 3 meses e 70 anos de idade.

Dentro dêsses limites foi verificado que para os grupos etários compreendidos entre 1 e 40 anos de idade, os valôres médios da proteinorraquia total se encontram próximos entre si. Não mostram tendência definida no sentido de aumento ou de diminuição que possam ser relacionados à idade. A concentração protêica é representada por valôres médios que se distribuem ao redor de 16 e $18 \mathrm{mg}$ por $100 \mathrm{ml}$. Êsses valôres estão muito próximos do valor médio normal referido para a taxa de proteinas totais na cisterna magna.

Abaixo de um ano de idade verifica-se tendência a ser maior a concentração protêica do LCR para os pacientes com idade entre 3 e 6 meses. A concentração protêica média, encontrada para êsse grupo foi de $23,9 \mathrm{mg}$ por $100 \mathrm{ml}$. A tendência a ser tanto maior a concentração protêica do LCR quanto menor a idade da criança pode decorrer de alterações do proteinograma. Segundo Widell ${ }^{8}$ é só na adolescência que o proteinograma do LCR atinge os caracteres peculiares à normalidade. Até essa época podem ser observadas maiores concentraçōes de certas frações protêicas do LCR (especialmente albumina) que podem acarretar aumento secundário do teor protêico total.

A partir dos 40 anos de idade foi verificado que a concentração média da proteinorraquia total tendia a aumentar sucessivamente, de um grupo etário para outro. Essa tendência se tornou mais nítida a partir dos 60 anos de idade. No último grupo etário explorado (pacientes com idade entre 66 e 70 anos) a concentração protêica do LCR era representada pela média de $24,0 \mathrm{mg}$ por $100 \mathrm{ml}$. Êsses dados vêm mostrar que a proteinorraquia total tende a aumentar com a idade. $O$ aumento é discreto, não ultrapassando os limites aceitos para as variações fisiológicas, pelo menos até 70 anos de idade, no material analisado.

Influência do sexo - Dencker e Zethraeus ${ }^{2}$ verificaram diferenças na proteinorraquia total que podem ser relacionadas ao sexo. Maiores taxas foram observadas de modo mais comum entre homens do que entre mulheres. A análise de 596 dos casos desta série, correspondentes aos grupos etários em que o sexo desempenha maior importância biológica (de 16 a 50 anos), permitiu comprovar o fato. Pelo quadro 2 verifica-se que os valôres encontrados para homens foram representados por média maior do que aquela referente às mulheres. A diferença entre elas foi significativa $(t=5,1)$. 


\section{RESUMO E CONCLUSOES}

Foi estudada a proteinorraquia total de 1.011 pacientes com LCR normal para investigar a influência da idade e do sexo. $O$ método empregado para a determinação da concentração protêica foi o turbidimétrico do ácido tricloracético.

A influência do fator etário foi estudada entre 3 meses e 70 anos de idade. Os resultados permitiram verificar que a concentração protêica do LCR é maior entre 3 e 6 meses de idade. Entre 1 e 40 anos de idade os valôres médios são próximos entre si, situando ao redor de 16 e $18 \mathrm{mg}$ por $100 \mathrm{ml}$. A partir de 40 anos de idade verifica-se tendência para ser progressivamente maior a proteinorraquia total. Essa tendência se acentua com o avançar da idade.

Em relação ao sexo, foi verificado que a proteinorraquia total tende a ser maior no homem do que na mulher. A diferença entre as médias encontradas para os homens e mulheres foi estatisticamente significante.

Esses dados confirmam observações anteriores, caracterizando-os em relação ao método empregado para a determinação da concentração protêica do LCR.

\section{SUMMARY}

Total protein content of the cerebrospinal fluid. Changes related to the age and to the sex.

The total protein content of the CSF of 1,011 cases was studied in order to explore the influence of the age and of the sex of the patients. The CSF samples studied were collected from the cisterna magna. They did not show changes regarding to pressure, aspect, color and cytology. Globulin tests were negative (Pandy and Takata-Ara) as well as complement fixation tests for syphilis and cysticercosis.

The protein content was determined by the trichloracetic acid method as proposed by Bossak and coworkers. The normal limits for physiologic changes were those determined by the study of another series of cases. These data were previously reported. The protein contents of the CSF samples studied in this publication are between such limits.

The influence of the age was studied between the limits of 3 months and 70 years. It was found that the mean values tend to decrease from the first group (patients 3-6 months old) until one year of age. From one to 40 years the CSF protein content shows no changes which may be related to the age. Above 40 years the protein content of the CSF tends to increase. This tendency is more marked among the elder patients. 
The influence of the sex was explored among people whose age varied from 16 to 50 years (596 of all the patients). The mean concentration of the CSF proteins found for men was higher than that found for women. This difference is statistically significant.

These data confirm the results registered by other authors. They permit to define such physiologic changes in respect to the method employed for the determination of the CSF protein content.

\section{REFERENCIAS}

1. BOSSAK, H. N.; ROSENBERG, A. A.; HARRIS, A. - A quantitative turbidimetric method for the determination of spinal fluid protein. J. Ven. Dis. Inform., 30:100-103 (abril) 1949. 2. DENCKER, S. J.; ZETHRAEUS, S. - Sex differences in total protein content of cerebrospinal fluid. Acta Psychiat. Scandinav., 36:76-82, 1961. 3. DINIZ, H. B. - Determinação da idade da criança em que o liquido cefalorraqueano atinge o padrão de normalidade do adulto. Tese de doutoramento, São Paulo, 1955. 4. MADONICK, M. J. - The total spinal fluid protein in patients over 65. Geriatrics 10:533-535 (novembro) 1955. 5. SPINA-FRANCA, A.; AMAR, I. Valôres normais da concentração protêica do liquido cefalorraquidiano cisternal. Arq. Neuro-Psiquiat., 15:27-34 (março) 1957. 6. SPINA-FRANÇA, A.; AMAR, I. Valôres normais da concentraçâo protêica do líquido cefalorraquidiano: variações ligadas ao local de colheita da amostra. Arq. Neuro-Psiquiat., 19:220-225 (setembro) 1961. 7. SPINA-FRANÇA, A.; CERQUEIRA, F. M. C.; AMAR, I. - Proteinorraquia. Estudo crítico de métodos de dosagem. Arq. Neuro-Psiquiat., 13:303-312 (dezembro) 1955. 8. WIDELL, S. - On the cerebrospinal fluid in normal children and in patients with acute abacterial meningo-encephalitis. Acta Paediatrica (Uppsala) 47(supl. 115):1-102 (maio) 1958.

Clínica Neurológica - Faculdade de Medicina da USP - Caixa Postal 3461 São Paulo, SP - Brasil. 